\title{
LIFE SATISFACTION AMONG OLD AGED PEOPLE ATTENDING FAUJI FOUNDATION HOSPITAL
}

\author{
Mehwish Riaz, Abida Sultana, Aisha Tariq \\ Foundation University Medical College Islamabad, Pakistan
}

\begin{abstract}
Objective: To determine life satisfaction in old age people attending Fauji Foundation Hospital and to assess relationship of socio-demographic variables on life satisfaction of old aged people.

Study Design: Cross sectional study.

Place and Duration of Study: Fauji Foundation Hospital Rawalpindi, from Feb to Aug 2018.

Methodology: A total of 347 individuals were included by using non-probability consecutive sampling. The participants of the 60 years or more attending Fauji foundation hospital, being mentally sound and having comprehensive understanding without hearing aid were included in the study. Questionnaire was given to respondents including demographic profile and Urdu version of Life Satisfaction Scale for assessing the life satisfaction in old age.

Results: The total sample mean life satisfaction score was $14.95 \pm 6.54 .5(1.5 \%)$ people were extremely satisfied, $27(8.4 \%)$ were satisfied, 117 (36\%) were dissatisfied and 63 (19.1\%) were extremely dissatisfied.

Conclusion: Life satisfaction was found statistically significant with female gender, older age 70-80 years, being un married, primary education, monthly income of less than 10,000 and being unemployed.
\end{abstract}

Keywords: Fauji foundation hospital rawalpindi, Life satisfaction, Life satisfaction scale, Old age.

How to Cite This Article: Riaz M, Sultana A, Tariq A. Life Satisfaction Among Old Aged People Attending Fauji Foundation Hospital. Pak Armed Forces Med J 2021; 71(5): 1751-1754. doi: https://doi.org/10.51253/pafmj.v71i5.2981

This is an Open Access article distributed under the terms of the Creative Commons Attribution License (https://creativecommons.org/licenses/by-nc/4.0/), which permits unrestricted use, distribution, and reproduction in any medium, provided the original work is properly cited.

\section{INTRODUCTION}

Due to decreasing fertility and increasing life expectancy, nations are greying as the elderly population is growing much faster than the overall population. ${ }^{1}$ At present, 8.5 percent of the world's Population is 60 years above. ${ }^{2}$ According to a recent report, 'An Aging World: 2015 , this figure will escalate to nearly $17 \%$ of the world's population by $2050 .{ }^{3}$ In the Eastern Mediter-ranean Region it is forecasted that by 2025, elderly will make up nearly $8.7 \%$ of the population ${ }^{1}$. In present, Pakistan is going through the demographic transition. ${ }^{4}$ It is expected that in 2025, Pakistan will have 42.8 million elderly people, which makes the ratio $12.4 \%$ of its population. Despite its political and economical issues, Pakistan has succeeded in improving life expectancy, a fact clearly evident of its growing elderly. ${ }^{5}$ In general, the age of 65 and above is considered to be the inception of senility. ${ }^{6}$

Initially the notion of satisfaction with life was suggested by Neugarten in 1961. For assessing successful aging most widely used concept is satisfaction with life. ${ }^{7}$ A strong association between subjective well-

Correspondence: Dr Mehwish Riaz, Dept of Community Medicine, Foundation University Medical College, Islamabad Pakistan

Received: 02 Jul 2019; revision received: 28 Jul 2020; accepted: 30 Jul 2020 being and life satisfaction is present in the matter of successful or active ageing8. According to Easterlin, significant correlates of high level of life satisfaction are, positive life events, good jobs, healthy interpersonal relationships, better physical and mental health and high income. ${ }^{9}$ Life satisfaction generally remained stable throughout the life span, showing just a slight increasing trend between the ages of 20 and 80 years. ${ }^{10}$

The objective of our research was to determine the life satisfaction in old people visiting Fauji Foundation Hospital Rawalpindi and to assess relationship of socio demographic variables on life satisfaction of old aged people. We attempted to find the socio-economic and psychological effect of living standards on an old person's mind to analyze his level of satisfaction in life. In Pakistan, past studies were done to know life satisfaction in institutionalized old age people but there was lack of research on a community level. There is a dire need for planning interventions to improve satisfaction of life in our senior citizens. Our research aimed to highlight the factors responsible for improving the life satisfaction in elderly which will eventually lead to a greater number of satisfied old members of the community and a healthier environment for them to live in. 


\section{METHODOLOGY}

This cross sectional study was conducted on patients attending OPD Fauji Foundation Hospital from February to August 2018 using non-probability consecutive sampling.

Inclusion Criteria: Old age people of 60 years or greater, mentally sound and having comprehensive understanding without hearing aid.

Exclusion Criteria: Non-consenting patients were excluded.

Sample size by calculated by using WHO sample size calculator by inserting confidence level of $95 \%$, pooled standard deviation of 5.7, population mean score of $15.7,11$ sample size of 347 was calculated. Individuals who were $<60$ years of age, had severe cognitive dysfunction or any chronic disease were excluded from the study. Acceptance was taken from ethical review committee of institution (no.217/FF/ FUMC/ ERC). After signing the informed consent form, a questionnaire was given to respondents including demographic pro-file and Urdu version of Life Satisfaction Scale 11 for assessing life satisfaction in old age.

The Satisfaction With Life Scale (SWLS) by Diener is a short 5-item instrument designed to measure global cognitive judgments of satisfaction with one's life. Scale consisted of five questions i.e. In most ways my life is close to my ideal, The conditions of my life are excellent, I am satisfied with life, So far I have gotten the important things I want in life, If I could live my life over, I would change almost nothing. Responses varied from 1-7 ranging from strongly agree to strongly disagree. Following cut offs were used to assess level of life satisfaction. About 31-35 Extremely satisfied, 26-30 satisfied, 21-25 slightly satisfied, 20 neutral, 15-19 slightly dissatisfied, 10-14 dissatisfied, 5-9 extremely dissatisfied ${ }^{12}$.

Data was analyzed using Statistical Package of Social Sciences (SPSS-23). descriptive statistics were carried out for demographic variables. Mean life satisfaction score with standard deviation was calculated. Independent sample t-test was used to compare life satisfaction score with age, gender, employment status, residence and family structure while ANOVA was used for comparing life satisfaction score with education status, monthly income and marital status.

\section{RESULTS}

A total of 325 participants were included in the study. Out of 85 performas which were incomplete were excluded from the study Mean life satisfaction score was found to be $14.95 \pm 6.5$. Among these, 142 $(43.7 \%)$ were self-employed. $59(18.2 \%)$ had pension as their source of income, $103(31.7 \%)$ were corporate employed and 21 (6.5\%) earned through armed forces. Majority were having 3 or 4 children i.e $78(24 \%)$ and $65(20 \%)$ respectively. Other important demographic characteristics of sample were given in Table-I. Out of 325 participant $5(1.53 \%)$ were Extremely satisfied, 62 $(19.07 \%)$ extremely dissatisfied, $27(8.30 \%)$ satisfied, $117(36 \%)$ dissatisfied, 26 (8.03\%) slightly satisfied, 76 $(23.38 \%)$ slightly dissatisfied and $12(3.69 \%)$ Neutral Table-II.

Table-I: Demographic characteristics of respondent.

\begin{tabular}{|c|c|}
\hline Demographic Characterstics & n (\%) \\
\hline \multicolumn{2}{|l|}{ Gender of Respondent } \\
\hline Male & $199(61.2)$ \\
\hline Female & $126(38.8)$ \\
\hline \multicolumn{2}{|l|}{ Age of Respondent } \\
\hline $60-70$ years & $260(80.0)$ \\
\hline $70-80$ years & $65(20.0)$ \\
\hline \multicolumn{2}{|l|}{ Education of Respondent } \\
\hline Primary & $116(35.7)$ \\
\hline Secondary & $69(21.2)$ \\
\hline Inter & $62(19.1)$ \\
\hline Bachelors & $41(12.6)$ \\
\hline Higher education & $37(11.4)$ \\
\hline \multicolumn{2}{|l|}{ Monthly Income } \\
\hline$<10,000 \mathrm{Rs}$ & $83(25.5)$ \\
\hline $11,000-20,000 \mathrm{Rs}$ & $61(18.8)$ \\
\hline $21,000-30,000 \mathrm{Rs}$ & $58(17.8)$ \\
\hline $31,000-40,000 \mathrm{Rs}$ & $50(15.4)$ \\
\hline $41,000-50,000 \mathrm{Rs}$ & $30(9.2)$ \\
\hline$>50,000 \mathrm{Rs}$ & $43(13.2)$ \\
\hline \multicolumn{2}{|l|}{ Marital Status } \\
\hline Single & $22(6.8)$ \\
\hline Married & $275(84.6)$ \\
\hline Divorced & $6(1.8)$ \\
\hline Widowed & $22(6.8)$ \\
\hline \multicolumn{2}{|l|}{ Employment of Respondent } \\
\hline Yes & $140(43.1)$ \\
\hline No & $185(56.9)$ \\
\hline \multicolumn{2}{|l|}{ Residence of Respondent } \\
\hline Rural & $118(36.3)$ \\
\hline Urban & $207(63.7)$ \\
\hline \multicolumn{2}{|l|}{ Family Structure } \\
\hline Nuclear & $161(49.5)$ \\
\hline Joint & $164(50.5)$ \\
\hline \multicolumn{2}{|c|}{ Table-II: Categorization of life satisfaction score. } \\
\hline Categorization of score & n (\%) \\
\hline Extremely satisfied & $5(1.53 \%)$ \\
\hline Satisfied & $27(8.30 \%)$ \\
\hline Slightly satisfied & $26(8.03 \%)$ \\
\hline Neutral & $12(3.69 \%)$ \\
\hline Slightly dissatisfied & $76(23.38 \%)$ \\
\hline Dissatisfied & $117(36 \%)$ \\
\hline Extremely dissatisfied & $62(19.07 \%)$ \\
\hline
\end{tabular}


Life satisfaction score was found to be statistically significant with older age 70-80 years ( $p$-value 0.007 ), female gender ( $p$-value 0.001), monthly income less than $10,000(p$-value $<0.001)$, being single $(p$-value $<0.001$ ), unemployment ( $p$-value 0.04). Education of respondent showed that there was a significant difference between primary education and other education levels $(p<0.001)$. F $(4,317)=11.420, p$-value $<0.001$.

Gamez Howell of marital status revealed that there was statistically significant difference of mean score between single $(19.63 \pm 9.04, p$-value $=0.05)$, widowed $18.77 \pm 7.28, p$-value=0.04). Gamez Howell of monthly income showed significant difference of monthly income $<10,000(\mathrm{M}=19.57 \pm 6.60, p$-value $\leq 0.001)$ with other monthly income groups shown in Table-III.

Table-III: Comparison of life score with sociodemographic variables.

\begin{tabular}{|c|c|c|c|}
\hline & $\mathbf{n}$ & Mean \pm SD & $p$-value \\
\hline \multicolumn{4}{|l|}{ Age of Respondent } \\
\hline $60-70$ years & 259 & $14.47 \pm 6.53$ & \multirow{2}{*}{$0.009^{*}$} \\
\hline $70-80$ years & 65 & $16.90 \pm 6.27$ & \\
\hline \multicolumn{4}{|c|}{ Gender of Respondents } \\
\hline Male & 199 & $13.82 \pm 5.89$ & \multirow{2}{*}{$<0.001^{*}$} \\
\hline Female & 126 & $16.73 \pm 7.13$ & \\
\hline \multicolumn{4}{|c|}{ Education of Respondents } \\
\hline Primary & 115 & $18.02 \pm 6.84$ & \multirow{5}{*}{$<0.001^{* *}$} \\
\hline Secondary & 69 & $13.50 \pm 5.47$ & \\
\hline Inter & 62 & $13.90 \pm 5.81$ & \\
\hline Bachelors & 41 & $12.02 \pm 6.04$ & \\
\hline Higher education & 37 & $13.21 \pm 5.77$ & \\
\hline \multicolumn{4}{|l|}{ Monthly Income } \\
\hline$<10,000 \mathrm{Rs}$ & 83 & $19.57 \pm 6.60$ & \multirow{6}{*}{$<0.001^{* *}$} \\
\hline $11,000-20,000 \mathrm{Rs}$ & 60 & $15.11 \pm 6.40$ & \\
\hline $21,000-30,000 \mathrm{Rs}$ & 58 & $13.68 \pm 5.39$ & \\
\hline $31,000-40,000 \mathrm{Rs}$ & 50 & $12.24 \pm 5.43$ & \\
\hline $41,000-50,000 \mathrm{Rs}$ & 30 & $13.63 \pm 5.36$ & \\
\hline$>50,000 \mathrm{Rs}$ & 43 & $11.67 \pm 5.28$ & \\
\hline \multicolumn{4}{|l|}{ Marital Status } \\
\hline Single & 22 & $19.63 \pm 9.04$ & \multirow{4}{*}{$<0.001^{* *}$} \\
\hline Married & 274 & $14.21 \pm 6.01$ & \\
\hline Divorced & 6 & $18.33 \pm 5.35$ & \\
\hline Widowed & 22 & $18.77 \pm 7.28$ & \\
\hline \multicolumn{4}{|c|}{ Employment of Respondent } \\
\hline Yes & 140 & $13.20 \pm 5.80$ & \multirow{2}{*}{$<0.001^{*}$} \\
\hline No & 185 & $16.27 \pm 6.77$ & \\
\hline \multicolumn{4}{|c|}{ Residence of Respondent } \\
\hline Rural & 118 & $15.30 \pm 6.59$ & \multirow{2}{*}{$0.43^{*}$} \\
\hline Urban & 207 & $14.74 \pm 6.52$ & \\
\hline \multicolumn{4}{|l|}{ Family Structure } \\
\hline Nuclear & 161 & $14.70 \pm 7.03$ & \multirow{2}{*}{$0.57^{*}$} \\
\hline Joint & 164 & $15.18 \pm 6.03$ & \\
\hline
\end{tabular}

\section{DISCUSSION}

Life satisfaction among geriatric population has become an important issue in elderly care. Elderly population is neglected now a days by communities and families due to demanding jobs, Change in life styles, a shift to nuclear family structures. ${ }^{12}$ The objective of our study was to assess life satisfaction in elderly population of Rawalpindi Pakistan in relation with sociodemographic variables. The expansion of modernization and the increased aging population throughout the world has made it important to investigate in the field of gerontology. ${ }^{11}$

Life satisfaction is a multi-dimensional issue. ${ }^{13}$ In this study $78 \%$ population was found to be dissatisfied from their life including 23\% slightly dissatisfied, 36\% dissatisfied and $19.1 \%$ were extremely dissatisfied, These results were far more alarming than the study conducted in Turkey by Beyaztas et al, where 36.6\% were not found to be satisfied with their lives. The difference in responses might be due to better living standards in Turkey. ${ }^{14}$

In this study Life satisfaction score was higher in females as compared to males, this might be due to better socialization and stress coping by females in our sample population .These results were consistent with results of Sheung-Tak and Chan, ${ }^{15}$ who discovered that social networking has more influence upon female Life satisfaction comparing to male and Vinsi M.S also revealed the findings that the life satisfaction level was high and satisfactory in female old age populations in comparison to males geriatrics staying in old age home ( $Z$ test score greater than tabulated value $5.8>1.96$ ). ${ }^{16}$

In this study, Life satisfaction score was statistically significant with monthly income. Mean score of life satisfaction decreases as monthly income increases, these results were contrary with research work of Jiménez et al, which suggested that life satisfaction increases as moving to high income group $(p<0.01)^{17}$. Current study showed life satisfaction was high in those individuals who have primary education; while a cross country survey by De-Neve et al. found positive effect of high education on life satisfaction ${ }^{18}$, these both results might be due to psychological acceptance of people regarding their education and income.

In present study statistically significant relationship was found between life satisfaction and marital status. Score was highest in single person these results were contrary to researches done by Zakaria et al which showed ore life satisfaction with being married ( $p$-value $<0.05),{ }^{19}$ the difference might be due to marital status affecting their life decisions and positions. Our study showed statistically significant relationship between un employment and life satisfaction score, unemployed individuals were more satisfied with their 
lives these results were very surprising as study in China showed that employment in general, and certain work, were related to life satisfaction among middleand old-aged Chinese. ${ }^{20}$ More studies are required to explore this variable.

This study has certain limitations that data was collected short period of time and in hospitals, more better results can be obtained if carried out in a with large sample size to generalize the results other aspects of life satisfaction in old age must be explored in our population.

\section{ACKNOWLEDGMENT}

We would like to acknowledge efforts of students of Batch D1 Fourth year MBBS 2017 for data collection and entries and old aged people who took part in our study and gave their precious time for data collection.

\section{CONCLUSION}

Life satisfaction was found statistically significant older age, female gender, being un married, primary education ,monthly income of less than 10,000 and being unemployed. These results are quite different from other researches published in past, more studies have to be done to explore these variables in detail to obtain local data.

\section{Conflict of Interest: None.}

\section{Authors' Contribution}

MR: Substantial contribution to the conception of the work, data analysis, Interpretation of data for the work; Drafting it critically for important intelletual content; Agreement to be accountable for all aspects ot the work, AS: Substantial contribution to the conception of the work, contribution in final manuscript and final approval of the version to be publication and agreement to be accountable for all aspects ot the work, AT: Contribution to the conception of the work, data entry and agreement to be accountable for all aspects of the work.

\section{REFERENCES}

1. World Health Organization. Health of the elderly. [internet] Available from: http://www.emro.who.int/entity/elderlyhealth/index.html [cited 2018 Nov 5].

2. National institute in aging. World's older population grows dramatically. National Institute on Aging NIA;2018], [internet] Available at:https://www.nih.gov/news-events/news-releases/ worlds-older-population-grows-dramatically [cited 18 Dec 2018]

3. He W, Goodkind D, Kowal P. In Aging World: 2015 International Population Reports [Internet] U.S. Census Bureau; 2015P95/16-1. [internet] Available from: https://www.census.gov/content/
dam/Census/library/publications/2016/demo/p95-161.pdf.[cited 15 Nov 2018 ].

4. Vertejee SS, Nasruddin N, Active ageing in Pakistan: challenges and opportunities. J Pak Med Assoc 2014; 64(1): 76-78.

5. Baig, L, Hasan Z, Iliyas M. Are the elderly in Pakistan getting their due share in health services? Results from a survey done in the peri-urban communities of Karachi. J Pak Med Assoc 2000; 50(6): 192-196.

6. Ozer M. A study on the life satisfaction of elderly individuals living in family environment and nursing homes. Turkish J Geriatric 2004; 7(1): 33-36.

7. Cleve R. "The multidimensional structure of the Life Satisfaction Index A and its application in research on aging [dissertation]. Iowa state university: Digital Repository @ Iowa State University; 1990, [internet] Available from: https://lib.dr. iastate.edu/ rtd/9884/ [cited 2018 December 28].

8. Au AM, Chan SC, Yip HM, Kwok YC, Lia KY, Leung KM, et al. Age-Friendliness and Life Satisfaction of Young-Old and OldOld in Hong Kong. Curr Gerontol Geriatr Res 2017; 2017(2): 6215917.

9. Easterlin RA. Life cycle happiness and its sources: Intersections of psychology, economics, and demography. J Econ Psychol 2006; 27(4): 463-482.

10. Akbar M, Akram M, Ahmed M, Hussain MS, Lal V, Ijaz S. Relationship between Resilience and Life Satisfaction among Nomadic. Int J Innovat App Stud 2014; 6(3): 515-529.

11. Diener E, Emmons RA, Larsen RJ, Griffin S. The Satisfaction with Life Scale. J Personal Assess 1985; 49(1): 71-75.

12. Chaudhary A. A study of life satisfaction and health in old age. Inter J Sci Res 2015; 4(1): 1276-1281.

13. Onishi C, Yuasa K, Sei M, Ewis AA, Nakano T, Munakata H. Determinants of life satisfaction in Japanese elderly women. J Med Invest 2010; 57(1-2): 69-80.

14. Beyaztas FY, Kurt G, Bolayir E. Life satisfaction level of elderly people: A field study in Sivas, Turkey. J Pak Med Assoc 2012; 62(3): 221-225.

15. Cheng ST, Alfred C, Chan M. Relationship With Others and Life Satisfaction in Later Life: Do Gender and Widowhood Make a Difference?. J Gerontolog Ser B 2006; 61(1): 46-53.

16. Vinsi MS. A comparative study to assess the life satisfaction level among male and female geriatrics living in selected old age homes of indore city. Int J Health Sci Health 2014; 4(5): 241-243.

17. Jiménez MMS, Artes J. Education as a Positional Good: A Life Satisfaction Approach. Soc Indic Res 2011; 103(3): 409-426.

18. De Neve JE, Ward G. Happiness at work, chap. 6, world happiness report 2017, [internet] Available from:https://www. academia. edu/38039513/WORLD_HAPPINESS_REPORT_2017 [Assessed at 26 July 2019].

19. Zakaria M, Kadir NB, Baharuddin KH, Marital status, career and income as indicators of life satisfaction among middle-aged career women in Hulu Langat, Selangor, Malaysia. Popul 2017; 25(1): 1-15.

20. Tang F, Chen H, Zhang Y, Mui AC. Employment and Life Satisfaction Among Middle- and Old-Aged Adults in China. Gerontol Geriatric Med 2018; 4(1): 1-8. 